\title{
Erratum to: Physics and Chemistry of Minerals Special Issue "Perovskite: A tribute to Roger H. Mitchell"
}

\author{
Catherine McCammon
}

Published online: 21 May 2014

(C) Springer-Verlag Berlin Heidelberg 2014

\section{Erratum to: Phys Chem Minerals (2013) 40:603-610, DOI 10.1007/s00269-012-0545-5 and Phys Chem Minerals (2013) 40:611-623, DOI 10.1007/s00269-013-0596-2}

Two papers from this Special Issue have been inadvertently published in an earlier issue of Physics and Chemistry of Minerals and are available online:

Crystal structures and phase transitions in $\mathbf{S r}_{2} \mathbf{I n}$ $\mathrm{TaO}_{6}$ perovskite

Qingdi Zhou, Brendan J. Kennedy, Maxim Avdeev

Abstract: The preparation and crystal structure of the double perovskite oxide $\mathrm{Sr}_{2} \mathrm{InTaO}_{6}$ are reported. This oxide has a monoclinic structure in space group $P 2_{1} / n$ at room temperature, where In and Ta display a rock-salt-type ordering with $a=5.73356(10), b=5.74052(10), c=8.10905(14) \AA$, and $\beta=90.022(6)^{\circ}$. Variable temperature neutron diffraction measurements demonstrate that this displays the sequence of phase transitions $P 21 / n \stackrel{605^{\circ} \mathrm{C}}{\longrightarrow} I 2 / m \stackrel{705^{\circ} \mathrm{C}}{\longrightarrow} I 4 / m \stackrel{930^{\circ} \mathrm{C}}{\longrightarrow} \mathrm{Fm} \overline{3} m$ as a consequence of the sequential loss of tilting of the corner-shared octahedra upon heating. The evolution of $\mathrm{Sr}_{2} \mathrm{InTaO}_{6}$ crystal structure upon heating is analyzed and described in terms of symmetry-adapted distortion modes. The GM4+ and X3+ that are responsible for anti-phase and in-phase tilting, respectively, are highly temperature-dependent, with the GM4+ mode having the largest amplitude at room temperature.

The online version of the original article can be found under doi:10.1007/s00269-012-0545-5, 10.1007/s00269-013-0596-2.

C. McCammon $(\bowtie)$

Bayerisches Geoinstitut, Universität Bayreuth, 95440 Bayreuth, Germany

e-mail: catherine.mccammon@uni-bayreuth.de
Pyrophanite pseudomorphs after perovskite in Perkupa serpentinites (Hungary): a microtextural study and geological implications

N. Zajzon, T. Váczi, B. Fehér, Á. Takács, S. Szakáll, T. G. Weiszburg

Abstract: Pyrophanite in serpentinite at Perkupa (Hungary) is described in detail for the first time as a replacement product of perovskite. It occurs as a $20-$ to $30-\mu \mathrm{m}-$ wide rim, mantling a remnant core composed of perovskite or its alteration products. The pyrophanite rim consists of an inner zone, representing a pseudomorph after perovskite, and an outer overgrowth zone. Raman mapping and electron backscatter diffraction data show that the pyrophanite rims typically represent single crystals rather than being composed of multiple domains in different crystallographic orientations. Perovskite occurs exclusively in the core of pyrophanite and was identified as the orthorhombic $\mathrm{CaTiO}_{3}$ phase, based on Raman spectra. Heterogeneous, polyphase mineral cores, consisting of calcite, anatase, and/or brookite, kassite, and Mn-bearing kassite, in some cases in association with relict perovskite, are typical in the larger pyrophanite-rimmed grains. The crystallographically coherent pyrophanite rims could have formed through a process where the precursor perovskite crystal acted as a structural template for the newly forming phase, that is, by interface-coupled dissolution reprecipitation during serpentinization of the precursor rock. This alteration of perovskite to pyrophanite was not complete, resulting in the presence of perovskite fragments enclosed in pyrophanite. During the metamorphic evolution of the rock, some of the remnant perovskite cores further altered to $\mathrm{TiO}_{2}$ polymorphs (anatase and brookite) and calcite, via transitional alteration products. 